\title{
Pattern of Sexually Transmitted Infections at Kohalpur Teaching Hospital
}

\author{
Pandey $\mathrm{S}^{1}$, Sharma $\mathrm{N}^{2}$, Pokhrel $\mathrm{N}^{3}$, Joshi $\mathrm{S}^{4}$
}

\begin{abstract}
Background: WHO estimated that approximately 448 million new cases of four main curable sexually transmitted infections (STIs), viz., gonorrhoea, syphilis, chlamydial infection, and trichomoniasis occur every year, nearly $80 \%$ of which in developing countries. STIs has proven role in facilitation of HIV infection and also increases susceptibility to other STIs. Most of the STIs, both ulcerative and non-ulcerative, are prevalent in Nepal and constitute one of the major health problem. Their epidemiological and clinical picture is being modified in the context of ongoing HIV/AIDS epidemic, especially during the last decade. Objectives: This study was undertaken to find out the pattern of sexually transmitted infections in Nepalgunj Medical College Teaching Hospital, Kohalpur. Method and material: This is a hospital - based descriptive study conducted in the Department of Dermatology, Venereology and Leprology of Nepalgunj Medical College Teaching Hospital, Kohalpur between August 2013 to July 2014 . A total of 52 patients were included in the study and verbal consent was taken. History and clinical examinations were performed and the data were recorded and analyzed. Results: Total of 52 patients were diagnosed with Sexually Transmitted Infections, out of which $75 \%$ were male and $25 \%$ were female. The most common diagnosis was gonorrhea (34.6\%) followed by condyloma accuminata (32.7\%), latent syphilis (15.4\%) non-gonococcal urethritis(9.6\%), vaginal discharge syndrome (5.8\%)and HIV (1\%). Age group 21 to 30 years were the maximum sufferers. Conclusion: Gonorrhoea still comprises a major bulk of STI in Nepalgunj Medical College Hospital, Kohalpur. Majority of the patients suffering from sexually transmitted infections were in the age group 21-30 years. A trend of sexual exposure during adolescence with multiple partners and inconsistent use of condoms was observed as a common factor in its promotion despite efforts from various sectors.
\end{abstract}

Key words: Prevalence, sexually transmitted infection

\section{INTRODUCTION}

STIs are infections that are spread primarily through person-toperson sexual contact. There are more than 30 different sexually transmissible bacteria, viruses and parasites. According to 2005 WHO estimates, 448 million new cases of curable STIs (syphilis, gonorrhea, chlamydia and trichomoniasis) occur annually throughout the world in adults aged 15-49 years. In developing countries, STIs and their complications rank in the top five disease categories for which adults seek health care ${ }^{1}$.

Due to lack of proper reporting system, STI/HIV data are scarce and nonspecific in Nepal. Around 200,000 episodes of STIs are estimated to occur annually in Nepal ${ }^{2}$. The older terminology of 'venereal diseases' (VDs) largely has been superseded in the past 50 years by 'sexually transmitted diseases' (STDs) and more recently by 'sexually transmitted infections' (STIs) ${ }^{3}$.

1. Dr. Sumit Pandey

2. Dr. Nirmala Sharma

3. Dr. Nitesh Pokhrel

4. Dr. Shambhu Joshi

Address for correspondence:

Dr. Sumit Pandey

Department of Dermatology

Nepalgunj Medical College Teaching Hospital

Kohalpur, Banke, Nepal

Email: sumitpandey207@yahoo.com
Sexually transmitted infection (STI) differs from sexually transmitted disease (STD) in that STD conventionally includes infections resulting in clinical diseases that may involve the genitalia and other parts of the body participating in sexual interaction, e.g., syphilis, gonorrhoea, chancroid, donovanosis, non-gonococcal urethritis, genital warts, herpes genitalis, etc. STI, in addition, includes infections that may not cause clinical disease of genitals but are transmitted by sexual interaction, e.g. all STDs and hepatitis B and C, HIV, HTLV-1, etc. Nowadays, the term STI is preferred, since it covers all the diseases that can be transmitted by sexual intercourse. However, for all practical purposes, both STI and STD are used synonymously ${ }^{4}$.

Despite the availability of effective treatment and preventive measures, STIs are still a major public health issue for both industrialized and developing countries. Recent trend indicates that incidence of STIs is increasing even in developed countries ${ }^{6}$.

The high prevalence of STIs in the developing countries are expected to be due to poverty and migration; change in sexual behavior; having multiple sex partners and sex trade; increased population of adolescents and young adults; substance abuse and peer pressure ${ }^{7,8}$. The rapid spread of HIV infection in developing countries has been attributed in part to high STI morbidity as a cofactor by enhancing the infectivity of HIVinfected people $e^{9,10}$.

It has been seen that improvement in the management of STIs can reduce the incidence of HIV infection in the general population by about $40 \%{ }^{11}$. 


\section{MATERIAL AND METHOD}

This is a Hospital based retrospective study conducted in the Department of Dermatology and Venereology, Nepalgunj Medical College Teaching Hospital Kohalpur. The sample size was 52 patients $75 \%$ (39) were male and $25 \%$ (13) female. The study group comprised of all the STI patients who presented to the Dermatology Department directly or were referred by other departments from August 2013 to July 2014. A thorough clinical history was elicited. Patients were asked about their symptoms, duration of their symptoms. Clinical examination included general physical examination followed by a meticulous examination of the external genitalia and the anal region. The inguinal region was inspected and palpated for evidence of lymphadenopathy. The number of genital ulcers, their location, size, floor, edges, presence or absence of tenderness, consistency, discharge and vesicles were noted. The external urethral meatus was inspected, in case of discharge; the origin of discharge was noted. . If no discharge was immediately apparent, then the urethra was milked out to note any discharge. Female patients were examined in detail in the presence of female assistant. The perineum, vulva, labia majora and labia minora were examined for any discharge, redness, swelling, excoriations, ulcers, warts, and any other skin lesions. If there was any vaginal discharge the colour, consistency and odour of the discharge was noted. The anal and perianal region were also examined. The sexual contact of the patient if available, were examined in an appropriate manner.

Following investigations were carried out:

1. Smears from the urethral discharge and from the genital ulcer was taken on a clean glass slide. The slide was stained with grams stain and examined for the prescence of polymorphonuclear leukocytes and the organisms with their staining characteristics.

2. Swab obtained from urethra/sub preputial groove in male and posterior vaginal fornix in female was dissolved in $10 \%$ potassium hydroxide and examined for candida.

3. Hanging drop preparation (wet mount) was done for the vaginal discharge.

4. Venereal Disease Research Laboratory (VDRL) test.

5. TPHA (Treponema Pallidum Hem-agglutination) test.

6. HIV (ELISA) in all the patients under study.

All patients were treated as per the diagnosis and counselled regarding the safe sexual practices and healthy living. Patients were also educated about the disease process and advised to visit the hospital for regular follow up. Patients were encouraged to get their sexual partners to the hospital and get them examined and treated accordingly. All statistical analysis was performed using the microsoft excel 2003 and SPSS 16 software program.

\section{RESULTS}

Among the 52 STI patients, 39 were males (75\%) and 13 were females $(25 \%)$ which is shown in figure 1 . Highest prevalence was seen among the age group $21-30$ years $(53.8 \%)$ as shown in figure 2. Gonorrhoea (34.6\%) was the most common diagnosis followed by condyloma accuminata (32.7\%), latent syphilis (15.4\%)non-gonococcal urethritis(9.6\%), vaginal discharge syndrome (5.8\%)and HIV (1\%) as shown in figure 3.

Female 13 (25\%)

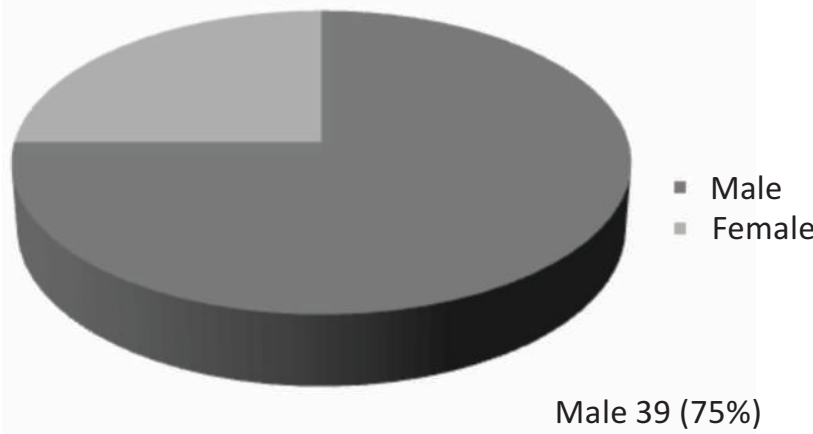

Figure 1: Gender distribution of patients

\begin{tabular}{|l|c|c|}
\hline Age of patient & Frequency & $\%$ \\
\hline $10-20$ & 4 & 7.7 \\
\hline $21-30$ & 28 & 53.8 \\
\hline $31-40$ & 14 & 26.9 \\
\hline $41-50$ & 4 & 7.7 \\
\hline $51-60$ & 2 & 3.8 \\
\hline Total & 52 & 100 \\
\hline
\end{tabular}

Table I: Age distribution

\begin{tabular}{|l|c|c|}
\hline Diagnosis & Frequency & $\%$ \\
\hline Latent Syphilis & 8 & 15.4 \\
\hline Gonorrhoea & 18 & 34.6 \\
\hline Condyloma Accuminata & 17 & 32.7 \\
\hline Non-gonococcal urethritis & 5 & 9.6 \\
\hline HIV & 1 & 1.9 \\
\hline Vaginal discharge syndrome & 3 & 5.8 \\
\hline Total & 52 & 100.0 \\
\hline
\end{tabular}

Table II: Pattern of STI

\section{DISCUSSION}

The global pandemic of HIV has very significantly affected the approach to treatment of sexually transmitted infections, as the most important mode of HIV transmission is heterosexual, 
and the sexually transmitted infections play a facilitative role in the acquisition and transmission of HIV $^{12}$. Apart from the risks of STIs, STIs are also an important determinant of increased HIV transmission. Incidence of various sexually transmitted infections has fluctuated over past several decades all over the world and shown some interesting long-term trends.

In industrialized countries, the bacterial STI (syphilis, gonorrhoea, chancroid) declined from the peak during the Second World War till up to the late fifties, then increased during the sixties and early seventies, and they have been decreasing again from the late seventies till the present. In the industrialized world, diseases due to Chlamydia trachomatis, genital herpes virus, human papillomaviruses, and human immunodeficiency virus are now more important than the classical bacterial ones; both groups remain major health problems in most developing countries. ${ }^{13}$ The present study was conducted at Nepalgunj Medical College Teaching Hospital Kohalpur.

A total of 52 patients were enrolled in the study from August 2013 to July 2014. Of the total 52 patients who were included in this study, male patients (75\%) were more than female patients $(25 \%)$ which is almost similar to a study done outside Nepal ${ }^{14}$ and in Nepal ${ }^{15}$. A demographic study done by Aich et al in Nepal also found male preponderance in HIV infection accounting for $86 \%{ }^{16}$.The male preponderance may be because of increased health seeking behaviour compared to females. The most common age group is between 21-40 years, which is similar to a study done by Banerjee et al ${ }^{17}$ and Devi et al ${ }^{18}$.

The higher number of patients in this age group 21-40 years is probably due to increased sexual activity. In this study gonorrhea (34.6\%) was the most common diagnosis followed by condyloma accuminata (32.7\%), latent syphilis (15.4\%)nongonococcal urethritis(9.6\%), vaginal discharge syndrome (5.8\%)and HIV (1\%) which is comparable to the study done by pokhrel D.B ${ }^{19}$.

\section{CONCLUSION}

The results concluded that bacterial STI (gonorrhoea) was the most common STI in this part of Nepal, however there is also an increase in the Viral STI (condyloma accuminata) which is the second most common diagnosis as shown in this study. The presence of untreated STIs (both those which cause ulcers and those which do not) increase the risk of both acquisition and transmission of HIV by a factor of up to 10. Prompt treatment for STIs is thus important to reduce the risk of HIV infection. Controlling STIs is important for preventing HIV infection, particularly in people with high-risk sexual behaviours.

\section{REFERENCES}

1. World health Organization. Sexually Transmitted Infections. Fact sheets no 110. Revised on 2011 August.

2. National Centre For AIDS and STD Control, Ministry Of Health,
2007 April.

3. Judson F. Introduction. In: Kumar B, Gupta S, editors, Sexually Transmitted Infections. 1st ed. Elsevier: New Delhi; 2005:1-4.

4. Sharma VK, Khandpur S. Epidemiology of sexually transmitted diseases. In: Sharma VK, editor. Sexually Transmitted Diseases and AIDS. Viva Books Pvt Ltd: New Delhi; 2003:1-41.

5. Thappa DM. History of venereal diseases and venereology in India. Indian J Sex Transm Dis 2002;23:67-79.

6. Fenton KA, Lowndes CM. The European Surveillance Of Sexually Transmitted Infections(ESSTI) Network. Recent Trends in the epidemiology of Sexually transmitted infections in the European Union. Sex Transmitted Infection 2004;80:255-63.

7. STD prevalence study among women in migrant communities of kailali district, Nepal. 2001. Subproject FCO No 846.

8. New Era/SACTS. STD and HIV prevalence survey among female sex workers and truckers on highway routes in terai, Nepal.2000.

9. Cohen MS, Hoffman IF, Royce RA. AIDSCAP Malawi Research Group. Reduction of concentration of HIV-1 in semen after treatment of urethritis: implications for prevention of sexual transmission of HIV-1. Lancet 1997;349:1868-73.

10. Cobett EL, Steketee RW, Kuile FO. HIV-1/AIDS and control of the other infectious diseases in Africa . Lancet 2002; 359:2177-87.

11. Bunnell RE,Dahlberg L, Rolfs R. High prevalence and incidence of sexually transmitted diseases in urban adolescent females despite moderate risk behavior.

12. Johannes Van Dam C. Sexually transmitted diseases and Hiv Infection; implications for control and prevention. Selections from JIMA 23-25 (Special issues on AIDS- vol. 91. No 12 1993, vol 92. 1994).

13. De Schryver, Meheus A. Epidemiology of Sexually Transmitted Diseases, the Global picture. Bull World Hith Orgn 1990;68:63954.

14. M Vibhu, K Ravindra V, H Bhawna. Profile of sexually transmitted infections in HIV positive patients. Indian J Sex Transm Dis 2004; Vol. 25 No.1,18-21.

15. Karn D, Amatya A, Aryal ER, KC S, Timalsina M. Prevalence of Sexually Transmitted Infections in a Tertiary Care Centre.Kathmandu Univ Med J 2011;34(2)44-8.

16. Aich TK, Dhungana M. Demographic and clinical profiles of HIV positive cases: a two year study report from a tertiary teaching hospital. J of Nepal Medical Association 2004; 43: 125-29.

17. S Banerjee, $S$ Halder, A Halder. Trend of sexually transmitted infections in HIV seropositive and seronegative males: A comparative study at a tertiary care hospital of north east india. Indian J Dermatol; march-april 2011; Vol 56(2) 239-41.

18. S Devi, TP Vetrichevvel, G A Pise, DM Thappa. Pattern of sexually transmitted infections in a tertiary care centre at Puducherry. Indian J Dermatol; 2009; Vol. 54: Issue 4: 347-9.

19. Pokhrel DB. Sexually Transmitted Infections, Sexuality and STI Stigma among Nepalese youth and adults. Nepal J Dermatol Venereol Leprol 2009;8(1):6-9. 